\title{
DIALOGISMO E COMUNICAÇÃO AUMENTATIVA ALTERNATIVA EM UM CASO
}

\section{Dialogism and augmentative and alternative communication}

\author{
Ana Rita Brancalioni ${ }^{(1)}$, Ana Clara Moreno ${ }^{(2)}$, Ana Paula Ramos de Souza ${ }^{(3)}$, Carla Ciceri Cesa ${ }^{(4)}$
}

\begin{abstract}
RESUMO
Tema: a evolução linguística de um sujeito com síndrome não esclarecida, caracterizada por prejuízos motores e ausência de fala, a partir da introdução do recurso da prancha de Comunicação Aumentativa Alternativa (CAA). Procedimentos: realizou-se um estudo de caso de um sujeito, que no início da pesquisa tinha 6 anos e 8 meses. O período estudado compreendeu agosto de 2007 a dezembro de 2008. Este sujeito já se encontrava em atendimento fonoaudiológico desde 2002, com queixa de escape de saliva e ausência de fala, apresentando poucas evoluções fonoaudiológicas, no que se refere à oralidade. Durante o período estudado, a intervenção fonoaudiológica preconizou a introdução da prancha de CAA em um funcionamento dialógico que incluiu a família e a escola. Foram realizadas avaliações observacionais por meio do PROC antes e após o período estudado. Resultados: a evolução do menino foi positiva tanto em relação à compreensão, quanto expressão linguística. O uso da CAA favoreceu o surgimento da fala. Tanto na família quanto na escola, foi possível perceber boa incorporação do uso desse recurso considerando a perspectiva teórica em que foi introduzido. Conclusão: a CAA, em uma perspectiva dialógica, apresentou-se com boa generalização de uso, o que permitiu avanços linguísticos no caso estudado.
\end{abstract}

DESCRITORES: Auxiliares de Comunicação para Deficientes; Barreiras de Comunicação; Linguagem Infantil; Patologia da Fala e Linguagem

\section{INTRODUÇÃO}

O estudo da comunicação aumentativa e alternativa (CAA) é uma área do conhecimento da prática clínica, educacional e de pesquisa reconhecida pela American Speech-Language-Hearing Association (ASHA) ${ }^{1}$, a qual disponibiliza uma diversidade

(1) Fonoaudióloga; Mestranda em Distúrbios da Comunicação Humana na Universidade Federal de Santa Maria, Professora Substituta do Curso de Fonoaudiologia da Universidade Federal de Santa Maria.

(2) Fonoaudióloga graduada pela Universidade Federal de Santa Maria; Consultório particular Santa Maria, RS.

(3) Fonoaudióloga; Docente da Graduação e do Programa de Pós-Graduação em Distúrbios da Comunicação Humana da Universidade Federal de Santa Maria; Doutora em Letras pela Pontifícia Universidade Católica do Rio Grande do Sul, RS.

(4) Fonoaudióloga; Docente da Faculdade Nossa Senhora de Fátima, Caxias do Sul, RS; Terapeuta clínica a domicílio, Porto Alegre, RS; Especialista em Motricidade Orofacial pelo CEFAC - Saúde e Educação; Mestre em Distúrbios da Comunicação pela Universidade Federal de Santa Maria.

Conflito de interesses: inexistente de técnicas, recursos e estratégias para compensar e facilitar, temporária ou permanentemente a comunicação e interação de sujeitos com algum impedimento ou dificuldade para a produção oral de fala. De modo especial, a CAA é apresentada em quadros clínicos, como a encefalopatia crônica não evolutiva da infância, autismo, entre outros distúrbios de linguagem e desenvolvimento.

Embora se observe considerável uso dos recursos da CAA na população infantil, ainda há pouca formação especializada sobre o tema no meio acadêmico ${ }^{2}$. Além isso, os profissionais que pretendem trabalhar com a CAA precisam colocar a linguagem em funcionamento, indo além do apontar/acionar um símbolo ou uma tecla ${ }^{3}$, é necessário a reflexão mais profunda sobre as concepções de língua, de linguagem e de sujeito ${ }^{4}$. Várias foram as adaptações realizadas para melhorar a utilização das pranchas de CAA ${ }^{4-7}$. Nesse contexto, novas propostas terapêuticas que busquem qualificar esse funcionamento são relevantes na pesquisa da CAA.

A realidade socioeconômica de países do primeiro mundo viabiliza recursos de CAA de alta 
tecnologia e tratamentos terapêuticos e educacionais, como se observa no programa assistencial do governo inglês, mas muito pode ser feito na realidade brasileira mesmo com baixa tecnologia ${ }^{8}$. A CAA é capaz de favorecer o uso da linguagem auxiliando na intervenção fonoaudiológica ${ }^{3,4,6}$ e psicológica, tornando-as mais eficazes ${ }^{9}$, assim como potencializa o processo de inclusão social e escolar ${ }^{10}$.

Alguns dos aspectos mais importantes na seleção, intervenção e generalização do uso da prancha de CAA podem ser resumidos em princípios de seleção e design do recurso e estratégias de intervenção com usuário e com este e seus familiares ${ }^{11-14}$. De um modo geral, afirma-se a necessidade de programação individual dos recursos tanto em relação à varredura quanto ao acesso e feedback.

Em relação às técnicas de intervenção em si não há comprovação com base em evidências acerca da efetividade do uso, mas vários estudos 4,11,15,16 apresentam consenso sobre a importância da inclusão familiar no processo terapêutico para que a generalização ocorra no uso da CAA, ou seja, que o uso da CAA seja efetivo fora do espaço terapêutico e demonstram que o uso da CAA se reflete no aumento da qualidade de vida familiar ${ }^{15}$. Boas intervenções permitem que, sobretudo as mães, possam acreditar no progresso das habilidades linguísticas do filho ${ }^{16}$, o que parece se comprovar em estudos que demonstram a melhora das habilidades de fala ${ }^{17}$ e escolares ${ }^{6}$.

Considerando tais estudos, este artigo, em uma perspectiva dialógica ${ }^{18}$, objetiva analisar a evolução linguística de um sujeito com síndrome não esclarecida, que apresenta prejuízos motores e ausência de fala, a partir da introdução do recurso da CAA. Os objetivos específicos são analisar a eficácia das estratégias implementadas junto à família, junto ao sujeito e à escola para a generalização de uso do recurso.

\section{APRESENTAÇÃO DO CASO}

Este estudo de caso se caracteriza por uma abordagem qualitativa, com enfoque retrospectivo e documental. Os dados descritos pertencem ao projeto de pesquisa "Clínica da Subjetividade nos Retardos da Aquisição da Linguagem Oral" o qual foi aprovado pelo Comitê de Ética em Pesquisa Institucional sob número 23081.010681/2007-41 e Certificado de Apresentação para Apreciação Ética - CAAE número: 0117.0.243.000-07. Ressalta-se que previamente a participação da criança no projeto, sua mãe assinou o Termo de Consentimento Livre e Esclarecido, o qual autorizou os dados clínicos coletados para pesquisa científica, desde que preservada a identidade da criança.

O sujeito em estudo neste artigo é E., sexo masculino, que no início da pesquisa tinha 6 anos e 8 meses. O período estudado compreendeu agosto de 2007 a dezembro de 2008. Este sujeito já se encontrava em atendimento fonoaudiológico desde 2002, encaminhado pela fisioterapeuta do Hospital Universitário Institucional, com queixa de escape de saliva e ausência de fala, apresentando poucas evoluções fonoaudiológicas, no que ser refere à oralidade. Durante o período estudado, o sujeito recebeu intervenção fonoaudiológica, por duas das autoras deste trabalho, sob supervisão e orientação das outras duas autoras deste estudo.

Conforme parecer neurológico, E. apresentava uma síndrome não esclarecida, mal-formações somáticas múltiplas e mal-formação cerebral do tipo atrofia, com hidrocefalia compensatória e atraso global do desenvolvimento incluindo funções neuromotoras e de linguagem.

$\mathrm{Na}$ avaliação fonoaudiológica realizada em agosto de 2008, tendo como suporte o protocolo de observação comportamental (PROC) $)^{19}$, o paciente iniciava a conversação somente por meio de gestos; respondia ao interlocutor, frequentemente, apenas com "sim" ou "não" com gestos, sendo que seu comportamento interativo/social tinha função regulatória. E. somente realizava vocalizações não articuladas, utilizava gestos simbólicos e compreendia até duas ordens não relacionadas.

Quanto ao aspecto de desenvolvimento cognitivo, E. explorava os objetos um a um de modo diversificado, sem uma organização dos mesmos e usava bonecos ou outros parceiros no brinquedo simbólico. Além disso, o paciente apresentava dificuldade na marcha (caminhava apenas com apoio) e atraso significativo na motricidade fina e ampla.

$\mathrm{Na}$ avaliação do sistema estomatognático, realizada com protocolo específico ${ }^{20}$, o paciente apresentava alterações quanto à mobilidade de língua, lábios, bochechas e mandíbula; mordida aberta anterior com apinhamento dentário; tensão reduzida de língua e escape de saliva extra-oral. Com relação às funções do sistema estomatognático, a sucção e a deglutição ocorriam com projeção lingual anterior e a mastigação envolvia movimentos lentos de amassamento do alimento.

Realizou-se avaliação audiológica objetiva por meio de emissões otoacústicas transientes (EOATs) e emissões otoacústicas por produto de distorçäo (EOAPDs), na qual o paciente apresentou EOATs e EOAPDs presentes em ambas as orelhas. Conforme relatos e observações $\mathrm{E}$. apresentava dificuldade em tolerar sons do dia-a-dia (latido de cachorro, música em alta intensidade, batida de 
porta) reagiando com choro e com o reflexo primitivo de "Startle" o que sugeria hipersensibilidade auditiva.

A partir de tais avaliações foi confirmando a hipótese diagnóstica de "Distúrbio de linguagem fazendo parte de um atraso global do desenvolvimento, e alteração do sistema estomatognático decorrentes de hidrocefalia e provável síndrome".

Tal perspectiva diagnóstica proporcionou uma intervenção centrada na linguagem oral expressiva, na estimulação dos órgãos e funções do sistema estomatognático e na psicomotricidade. A intervenção em linguagem, até o início do estudo, era focada na interação do brincar (simbolismo), no conto de estórias infantis e produção de onomatopéias cuja ênfase era a produção oral.

No entanto, a partir de uma perspectiva dialógica de linguagem, em agosto de 2007, buscou-se uma hipótese de funcionamento de linguagem ${ }^{21}$. Nesta observou-se que havia uma disposição de E. para enunciar, mesmo com poucos recursos de expressão, que eram, sobretudo, via corporal. Constatou-se também que a mãe conseguia interpretar os sinais corporais de E. e atribuir sentido aos mesmos. A partir de tal observação, hipotetizouse que a introdução da CAA favoreceria não só a comunicação e a linguagem, mas o desenvolvimento de E. de um ponto de vista global.

\section{RESULTADOS}

Os resultados serão apresentados em dois itens, o primeiro envolvendo a introdução da CAA e o segundo, os avanços obtidos pela CAA.

\section{Introdução da Comunicação Aumentativa e Alternativa}

Utilizando recursos de baixa tecnologia ${ }^{4,22}$, as pranchas de comunicação foram confeccionadas utilizando Símbolos de Comunicação Pictórica (PCS) ${ }^{14}$ do Boardmaker, fotografias, figuras de encartes promocionais de supermercados e de outros ramos do comércio, desenhos e escrita. Com a introdução da prancha de CAA a linguagem oral continuou sendo trabalhada, valorizando a intenção comunicativa e o uso das pranchas para expressar desejos, necessidade, ideias, fatos, em conjunto com gestos, expressões faciais e qualquer produção oral que pudessem veicular sentidos.

Em busca de consolidar a efetividade deste recurso, foram explicadas à mãe as possibilidades de uso e o benefício da CAA, bem como, a importância da mãe ser aliada e co-autora nas diferentes etapas do processo de implementação da CAA as quais são: seleção, criação, confecção, introdução, expansão, manutenção, generalização e interven- ção ${ }^{4}$. Neste aspecto, a mãe manifestou interesse e compreensão referindo: "tudo que eu puder fazer para ajudar o meu filho, eu farei". Assim, terapeuta e mãe tornaram-se parceiras e facilitadoras da comunicação de $\mathrm{E}$.

As pranchas eram confeccionadas pela terapeuta a partir de uma exploração com E. e sua mãe, sendo que esta, freqüentemente, solicitava a inclusão de símbolos. Nesse sentido, preconizou-se o trabalho de estratégias focadas no paciente e na família através de atendimento personalizado das necessidades dos mesmos ${ }^{11-14}$.

As alterações anatômicas (polidactilia e sindactilia) que o paciente apresentava, não dificultaram a técnica de seleção direta, através do apontar, contudo, essas alterações, prejudicavam o virar das pranchas na pasta, já que E. não realizava movimento de pinça superior. Neste aspecto trabaIhou-se juntamente com a terapeuta ocupacional a criação de recurso para permitir que a criança conseguisse realizar tal atividade sozinha. A solução se deu pela introdução de espátulas nas folhas da pasta para que E. pudesse virá-las sozinho.

A primeira prancha apresentada à criança foi confeccionada a partir de fotos de diversos brinquedos. Ao mostrar a prancha E. era capaz de identificar cada brinquedo, após nomeação pela terapeuta, em seguida, a criança era convidada a escolher um brinquedo na prancha, o qual the era oferecido após a escolha. No primeiro momento sem o uso da prancha os brinquedos permaneciam na sala e E. apontava para aquele que desejava brincar, já com o uso das pranchas os brinquedos ficavam fora do campo visual da criança. Na primeira sessão $E$. entendeu que precisava apontar na prancha a figura do brinquedo para recebê-lo, estava assim atribuído o uso das prancha para a função de solicitar. Interessante referir que o primeiro brinquedo apontado/escolhido por E. não fazia parte do repertório de brinquedos interpretados como "preferidos" da criança e não costumava estar na sala de terapia.

Com o uso das pranchas de CAA a promoção da linguagem por meio de onomatopéias também continuou sendo explorada. Confeccionou-se a prancha com animais, onde E. identificava os mesmos aos respectivos nomes e sons. A criança passou a atribuir funções aos animais, por meio de gestos e expressões faciais. Durante uma sessão, observouse que E. estava com a mão arranhada e questionou-se o que havia acontecido, o menino apontou para a figura que representava um gato e a mãe confirmou que o gato o havia arranhado.

A partir da CAA foram trabalhadas as categorias: pessoas: membros da família, amigos e o uso do pronome pessoal eu; substantivos: brinquedos, 
comidas, lugares e animais; descritores: sentimentos; verbos: generalidades, limpeza e higiene. E ainda, os números, as vogais e entre outras noções básicas de linguagem importantes para o dia-a-dia. Procurava-se criar situações em contextos reais de uso para a inserção da prancha, como, por exemplo, ir à cantina e solicitar à atendente o lanche utilizando as pranchas de CAA.

A prancha de CAA foi entregue à mãe apenas quando E. passou a procurá-la nas sessões para solicitar ou narrar algum acontecimento e, quando sua mãe mostrou interesse em levá-la para casa. Ressalta-se, novamente, o empenho da mãe no processo do uso das pranchas, que participava de todas as sessões fonoaudiológicas, ora como observadora, ora como colaboradora. Como já referenciado, a mãe, frequentemente, solicitava a inclusão de símbolos, pertencentes a diversas categorias. No início a inclusão de símbolos envolvia as necessidades básicas (símbolo de fralda, água, fome, abrir...) que a mãe referia ser importante para a criança utilizá-la na escola. Num segundo momento, a inclusão de símbolos, além de mostrar uma preocupação em tornar a criança mais independente, manifestou interesse em representar 0 vocabulário e experiências da criança, favorecendo assim a possibilidade do discurso da criança.

É difícil avaliar a compreensão de uma criança, sem oralidade. Muitas vezes, se tem a tendência de subestimar a capacidade e o desempenho linguístico dessa criança ${ }^{9}$. Isso também foi visto no caso de E., no qual ao apresentar as pranchas dos números, a criança revelou conhecer os mesmos e responder corretamente para sua idade. Ainda, ao trabalhar a prancha das vogais, E. soube reconhecer as mesmas e identificar a inicial do seu nome.

$\mathrm{Na}$ busca de aumentar as possibilidades de comunicação e maior independência da criança, incentivou-se o uso das pranchas de CAA na escola, na equoterapia e nas sessões de fisioterapia e de terapia ocupacional. Houve uma boa acolhida da prancha em tais ambientes, sobretudo na escola, ambiente em que se fazia possível uma aplicação mais ampla, conforme observação escolar em 2008. O investimento da professora e dos colegas em E. aumentou com o uso da prancha ${ }^{6}$.

As atualizações da prancha foram constantes, com a inclusão de símbolos/figuras dos desenhos favoritos na televisão, cantores, vestuário usual, sempre de acordo com as necessidades comunicativas individuais e com a participação da família.

\section{Avanços Obtidos pela Comunicação Aumentativa e Alternativa}

Por meio da CAA, E. demonstrou os seus sentimentos, como quando estava feliz, chateado, triste e até mesmo com frio. Inclusive, em uma das sessões fonoaudiológicas, a mãe referiu que não sabia o motivo de E. ter chorado quando estava na hidroterapia. Quando questionado pela terapeuta e solicitado a mostrar o motivo através das pranchas, o paciente apontou para aquela que indicava que estava com frio. Mostrou ainda que gostava de sorvete e que este também era frio. Já em outra sessão, apontou para a prancha que indicava que estava chateado. A terapeuta questionou o menino do porquê desse sentimento. E. colocou a mão em seu rosto, e sua mãe explicou que o gato de estimação havia arranhado a sua face no dia anterior.

Outras situações interessantes, também foram enunciadas por intermédio das pranchas. Em uma sessão, durante a exploração da pasta, E. indicou a prancha referente a banheiro, olhou para a terapeuta e sua mãe, e sorriu. Imediatamente, a terapeuta perguntou ao paciente se este desejaria ir ao banheiro, sendo a resposta positiva. Ambas conduziram o paciente até o banheiro. Este, após entrar no local, sorriu e saiu logo em seguida. Somente nesse momento, a terapeuta e sua mãe perceberam que $E$. não desejava ir ao banheiro. A expressão de seu rosto confirmou o que foi compreendido pela terapeuta: E. utilizou a CAA para sair da sessão, sendo que o seu objetivo era brincar com a gaita (seu brinquedo favorito), na sala de materiais.

Durante a intervenção terapêutica, percebeuse crescimento do processo de compreensão da linguagem. E. demonstrou compreender uma pequena narrativa oral inteira. Com a introdução da CAA e uso das pranchas, percebeu-se aumento da intenção/atitude comunicativa, das vocalizações, onomatopéias e emissões dos fonemas: $/ \mathrm{t} / \mathrm{/} / \mathrm{k} /, / \mathrm{m} /$, /b/, /g/ e /n/.

O paciente passou a produzir palavras e sílabas, tais como, ['tudu] - tudo; [gu'gu ] - Gugu; [a'o] - alô; ['ko] - robô, [ 't fin] - sim; ['mã te'te] - mãe Tete (sua mãe); ['mã 'na] - mãe da Ana, [ma'ñe] - manhe; ['ete] - esse; ['taj] - pai; [ 'gui] - Guilherme; [ ka'ka] Kaká (jogador de futebol), ['ajta] - gaita.

A Figura 1 mostra os resultados do PROC ${ }^{18}$ realizado em agosto de 2007 e dezembro de 2008, período do estudo.

Com relação à motricidade oral, o principal enfoque foi para a diminuição do escape de saliva, com a promoção do vedamento labial, crioestimulação, utilização de massagens e de manobras facilitadoras. Além disso, foram realizados exercícios isométricos e isotônicos de língua, bochechas e lábios. Quanto às funções do sistema estomatognático, foram enfocadas a sucção, deglutição e mastigação. A família foi orientada sobre a importância de manter uma adequada higiene oral e de estimular a mastigação. Os resultados obtidos também foram 
muito satisfatórios, com diminuição acentuada do escape de saliva e aumento das possibilidades de movimentação orofacial.

Além disso, o paciente mostrou avanços na marcha e no controle postural, devido à cirurgia de mal formação congênita dos pés e os diversos tratamentos realizados (fisioterapia, equoterapia, hidroterapia e terapia ocupacional). Esse avanço também foi verificado pelo neurologista, que descreveu no parecer neurológico de $\mathrm{E}$. uma evolução favorável na neuromaturação, com aquisição de marcha livre e suas variações. Além, de melhora na comunicação pela capacidade de entender/associar o que se fala e atender ordens com facilidade, apesar das suas dificuldades motoras.

\section{DISCUSSÃO}

Teve-se o cuidado para que os símbolos da CAA não fossem "ensinados" como, geralmente, observa-se nas práticas comportamentalistas e/ ou cognitivistas em Fonoaudiologia. Foram então, utilizadas as premissas da orientação dialógica de Bakhtin ${ }^{23}$, nas quais forma, uso e sentido são elementos metodológicos fundamentais para se configurar $\mathrm{o}$ ato enunciativo.

Tal concepção dialógica em linguagem pode melhor subsidiar a intervenção na clínica com o recurso da CAA ${ }^{4}$, pois dá-se ao "símbolo" (na verdade um sinal) um estatuto de signo, que é atualizado no contexto de uso entre os falantes, mesmo na ausência ou na restrição da oralidade, como o caso em questão.

A situação descrita na seção anterior, na qual o menino fez uso do sinal de CAA "banheiro" como um signo (para na realidade poder sair da sala de terapia e não ir ao banheiro), ilustra claramente que ele está posto num funcionamento de língua. Tal funcionamento foi favorecido e ampliado durante a intervenção fonoaudiológica com uso da CAA numa visão dialógica, assim como preconiza um estudo ${ }^{4}$.

Assim, E. passou a assumir um papel de enunciador ativo durante a interação social e linguística, demonstrando que a linguagem é heterogênea e multiforme ${ }^{21}$. Nesta perspectiva a ausência de oralidade não significa que não haja linguagem ou que o sujeito esteja excluído da língua e do discurso ${ }^{4,6}$.

Através da CAA uma série de conhecimentos que E. possuía, mas que pela ausência de recursos para expressá-los não eram percebidos pela terapeuta ou seus familiares, foram descobertos. Ainda, o aumento da crença nas habilidades linguísticas de $\mathrm{E}$. foi crescendo com o uso da prancha, bem como a qualidade de vida familiar ${ }^{13,14}$.

E. atribuiu associações diferentes para um mesmo sinal "gato", que num primeiro momento, serviu para identificar um animal, que emite determinado som. Já num segundo momento, esse mesmo sinal serviu para narrar a origem de seu arranhão. Utilizando-se o dialogismo de Bakhtin pode-se observar que o sinal "gato" foi um índice de inúmeras significações. Tal movimento de sinal a signo dá-se exclusivamente durante a enunciação, a qual é da ordem do irrepetível, ao passo que os enunciados são elementos reiteráveis e idênticos, portanto, convencionalmente definidos ${ }^{24}$.

Isso demonstra que a conexão entre o sinal que está na prancha e o sentido é ampla, pois no uso diário entre os interlocutores os sinais assumirão status de signo na negociação de sentidos entre os mesmos ${ }^{23}$. Ressalta-se em ambos os exemplos terapêuticos discutidos o caráter polissêmico do signo, manifesto no uso da prancha.

O fato da criança escolher, através da prancha, um brinquedo que não era tido como "preferido" pela terapeuta e pela mãe, evidencia que a prancha não pode limitar-se à inserção do conhecido e ser utilizada como uma confirmação do que já se sabe das preferências do usuário. Deve, ao contrário, ser inserida em diversos contextos ${ }^{25}$, com parceiros distintos ${ }^{11,12}$ e no diálogo, de modo que sempre surjam novas possibilidades do dizer, como prevê os deslocamentos teóricos que se faz da visão dialógica de Bakhtin para a Fonoaudiologia.

Os resultados encontrados evidenciam que a introdução da CAA favoreceu a expansão da linguagem, corroborando com achados de outros estudos ${ }^{3,4,6,7}$. Além disso, o avanço na produção oral, observado por E. também é evidenciado na literatura ${ }^{3,17}$.

Um aspecto bastante discutido com a implementação da CAA é determinar o momento ideal de entregar ao paciente a prancha para levá-la para casa. Um estudo ${ }^{7}$ refere que para isso acontecer é necessário que o paciente demonstre claramente que se apropriou adequadamente da mesma, utilizando-a como meio de auxiliá-lo a se comunicar. Quando isso não ocorre, possivelmente não terá validade levar a pasta para casa, uma vez que o paciente não irá utilizá-la.

Tal afirmativa pode ser repensada ao considerar a importância da introdução da CAA o mais precoce possível ${ }^{26}$, o uso em contextos formais e informais o qual favorece a incorporação do recurso no cotidiano ${ }^{25}$. O caso estudado sugere que o momento de entregar ao paciente pode ser singular e depende de outros aspectos como a participação da família durante o processo de implementação ${ }^{15,27}$. Durante todo o processo de intervenção incentivaram-se as práticas de generalização do uso ${ }^{28}$, em diferentes contextos e parceiros conversacionais, observando-se ganhos terapêuticos importantes no caso estudado. 


\begin{tabular}{|c|c|c|c|c|}
\hline \multicolumn{3}{|c|}{ ASPECTOS OBSERVADOS } & $\begin{array}{l}\text { RESULTADOS PROC } \\
\text { AGOSTO DE } 2007\end{array}$ & $\begin{array}{l}\text { RESULTADOS PROC } \\
\text { DEZEMBRO DE } 2008\end{array}$ \\
\hline \multirow{15}{*}{$\begin{array}{l}\text { HABILIDADES } \\
\text { COMUNICA- } \\
\text { TIVAS }\end{array}$} & \multirow{4}{*}{\multicolumn{2}{|c|}{$\begin{array}{l}\text { Habilidades } \\
\text { dialógicas ou } \\
\text { conversacionais }\end{array}$}} & $\begin{array}{l}\text { Intenção Comunicativa presente, } \\
\text { frequentemente, apenas por meio } \\
\text { de gestos simbólicos e apontar - } \\
\text { função regulatória. }\end{array}$ & $\begin{array}{l}\text { Intenção Comunicativa presente, } \\
\text { frequentemente, por meio de gestos } \\
\text { simbólicos, apontar - função regulatória; } \\
\text { de produção de sílabas e palavras; com } \\
\text { auxílio das pranchas de CAA. }\end{array}$ \\
\hline & & & $\begin{array}{l}\text { Inicia conversação, raramente, } \\
\text { apenas por meio de gestos. }\end{array}$ & $\begin{array}{l}\text { Inicia conversação, frequentemente, por } \\
\text { meio de gestos; de produção de sílabas e } \\
\text { palavras e com auxílio das pranchas de } \\
\text { CAA. }\end{array}$ \\
\hline & & & $\begin{array}{l}\text { Responde ao interlocutor apenas } \\
\text { sim ou não (movimento de } \\
\text { cabeça). }\end{array}$ & $\begin{array}{l}\text { Responde ao interlocutor, } \\
\text { frequentemente, além de sim ou não } \\
\text { (movimento de cabeça, e oralmente), } \\
\text { desejos, opiniões, sentimentos, por meio } \\
\text { de algumas produções orais e uso da } \\
\text { prancha de CAA. }\end{array}$ \\
\hline & & & Não realiza atividade dialógica. & $\begin{array}{l}\text { Realiza atividade dialógica, por meio de } \\
\text { gestos, algumas produções orais e } \\
\text { utilização das pranchas de CAA. }\end{array}$ \\
\hline & \multirow{7}{*}{$\begin{array}{l}\text { Funções } \\
\text { comunicativas }\end{array}$} & Instrumental & Presente, frequentemente. & Presente, frequentemente. \\
\hline & & Protesto & Presente, frequentemente. & Presente, frequentemente. \\
\hline & & Interativa & Presente, frequentemente. & Presente, frequentemente. \\
\hline & & $\begin{array}{l}\text { Nomeação } \\
\text { espontânea }\end{array}$ & $\begin{array}{l}\text { Presente, raramente, apenas por } \\
\text { meio de vocalizações não } \\
\text { articuladas. }\end{array}$ & $\begin{array}{l}\text { Presente, frequentemente, por meio de } \\
\text { produção de sílaba e palavras. }\end{array}$ \\
\hline & & Informativa & Ausente & $\begin{array}{l}\text { Presente, frequentemente, por meio de } \\
\text { produção de sílaba, palavras e uso das } \\
\text { pranchas de CAA. }\end{array}$ \\
\hline & & Heurítica & Ausente & $\begin{array}{l}\text { Presente, frequentemente, por meio de } \\
\text { produção de sílaba, palavras e uso das } \\
\text { pranchas de CAA. }\end{array}$ \\
\hline & & Narrativa & Ausente & $\begin{array}{l}\text { Presente, frequentemente, por meio de } \\
\text { produção de sílaba, palavras e uso das } \\
\text { pranchas de CAA. }\end{array}$ \\
\hline & \multirow{3}{*}{$\begin{array}{l}\text { Meios de } \\
\text { comunicação }\end{array}$} & $\begin{array}{l}\text { Meios não } \\
\text { verbais }\end{array}$ & $\begin{array}{l}\text { Somente vocalizações não } \\
\text { articuladas. }\end{array}$ & $\begin{array}{l}\text { Vocalizações não articuladas e } \\
\text { articuladas com entonação da língua } \\
\text { (jargão). }\end{array}$ \\
\hline & & $\begin{array}{l}\text { Meios não } \\
\text { verbais }\end{array}$ & Gestos simbólicos. & Gestos Simbólicos. \\
\hline & & $\begin{array}{l}\text { Meios } \\
\text { verbais }\end{array}$ & Ausência de oralidade. & Enunciado de duas palavras. \\
\hline & \multicolumn{2}{|c|}{$\begin{array}{l}\text { Níveis de contextualização } \\
\text { da linguagem }\end{array}$} & $\begin{array}{l}\text { Linguagem refere-se somente a } \\
\text { situações imediatas. }\end{array}$ & $\begin{array}{l}\text { Linguagem vai além da situação imediata, } \\
\text { referindo-se eventos mais distantes no } \\
\text { tempo. }\end{array}$ \\
\hline $\begin{array}{l}\text { COMPREEN- } \\
\text { SÃO VERBAL }\end{array}$ & & & $\begin{array}{l}\text { Compreende duas ordens não } \\
\text { relacionadas. }\end{array}$ & $\begin{array}{l}\text { Compreende ordens com três os mais } \\
\text { ações, solicitações, comentários e } \\
\text { estórias. }\end{array}$ \\
\hline \multirow{5}{*}{$\begin{array}{l}\text { ASPECTOS } \\
\text { DO } \\
\text { DESENVOL- } \\
\text { VIMENTO } \\
\text { COGNITIVO }\end{array}$} & \multicolumn{2}{|l|}{$\begin{array}{l}\text { Formas de } \\
\text { manipulação } \\
\text { dos objetos }\end{array}$} & $\begin{array}{l}\text { Explora os objetos um a um de } \\
\text { modo diversificado. }\end{array}$ & $\begin{array}{l}\text { Atua de maneira diversificada, sobre dois } \\
\text { ou mais objetos relacionando-o. }\end{array}$ \\
\hline & \multicolumn{2}{|c|}{$\begin{array}{l}\text { Nível de } \\
\text { desenvolvimento } \\
\text { do simbolismo }\end{array}$} & $\begin{array}{l}\text { Usa bonecos ou outros parceiros } \\
\text { no brinquedo simbólico. }\end{array}$ & $\begin{array}{l}\text { Cria símbolos fazendo uso de objetos } \\
\text { substitutos ou gestos simbólicos para } \\
\text { representar objetos ausentes. }\end{array}$ \\
\hline & \multicolumn{2}{|l|}{$\begin{array}{l}\text { Nível de } \\
\text { Organização } \\
\text { do brinquedo }\end{array}$} & $\begin{array}{l}\text { Manipula objetos sem uma } \\
\text { organização dos mesmos. }\end{array}$ & $\begin{array}{l}\text { Faz pequenos agrupamentos de dois ou } \\
\text { três objetos. }\end{array}$ \\
\hline & \multirow[t]{2}{*}{ Imitação } & Gestual & $\begin{array}{l}\text { Imitação de gestos/movimentos } \\
\text { não visíveis no próprio corpo. }\end{array}$ & $\begin{array}{l}\text { Imitação de gestos/movimentos não } \\
\text { visíveis no próprio corpo. }\end{array}$ \\
\hline & & Sonora & Tenta imitar onomatopéias & Imitação de palavras \\
\hline
\end{tabular}

Figura 1 - Resultados do PROC ${ }^{17}$ antes da introdução da CAA e após 16 meses de uso. 


\section{CONCLUSÃO}

Através da análise e discussão deste estudo de caso pudemos observar o impacto da mudança de paradigma que a visão dialógica de Bakhtin pode operar na clínica de linguagem, quando o fonoaudiólogo se alicerça nela para fazer circular sentidos múltiplos aos sinais até então fixos e imutáveis da prancha de CAA.

Observou-se também o quanto devemos valorizar e considerar a qualidade do desempenho da maternagem das mães de sujeitos com oralidade restrita ou ausente no processo de implementação do recurso, devendo então a terapêutica ter foco duplo na intervenção fonoaudiológica, não somente com atenção ao usuário.

Por fim, ressalta-se a importância de se personalizar a escolha do tipo, portabilidade e acessibilidade do recurso em si, além de alternar as práticas terapêuticas em contextos formais e informais com diferentes parceiros conversacionais. Esta promoção da generalização do uso do recurso incentiva e facilita a inclusão social e escolar, promovendo uma melhor qualidade de vida ao usuário e familiares.

\begin{abstract}
Background: the linguistic evolution of a subject with unknown syndrome, characterized by motor impairment and absence of speech after the introduction of Augmentative and Alternative Communication (AAC) board. Procedures: we performed a case study of a subject that was 6 years and 8 months old at the beginning of the study. The study period was from August 2007 to December 2008. The subject had already been undergoing speech-language therapy since 2002 , with complaint of saliva flow and absence of speech. He had little phonoaudiological progress in terms of orality. During the study period, the subject was given speech-language intervention through introduction of AAC in a dialogic functioning that involved his family and school. Observational assessments were performed using the PROC before and after the study period. Results: the subject's progress was positive in relation to understanding and linguistic expression. Use of AAC favored manifestation of speech. Both within the family and at school there was good incorporation of such resource, considering the theoretical perspective in which it was introduced. Conclusion: AAC, in a dialogic perspective, had good generalization of use, which enabled linguistic progresses in this case.
\end{abstract}

KEYWORDS: Communication Aids for Disabled; Communication Barriers; Child Language; SpeechLanguage Pathology

\section{REFERÊNCIAS}

1. American Speech Language Hearing Association. ASHA, Oxfordshire; 1991. Disponível em: URL: http://www.asha.org. Acesso em 10 jan 2009.

2. Ratcliff A, Koul R, Lloyd LL. Preparation in augmentative and alternative communication: an update for speech-language pathology training. Am J Speech Lang Pathol. 2008; 17:48-59.

3. Chun RYS. Comunicação suplementar e/ou alternativa: favorecimento da linguagem de um sujeito não falante. Pró-Fono. 2003; 15(1):55-64.

4. Cesa CC. A comunicação aumentativa e alternativa em uma perspectiva dialógica na clínica de linguagem [dissertação]. Santa Maria (RS): Universidade Federal de Santa Maria; 2009.

5. Miranda IC, Gomes ICD. Contribuições da comunicação alternativa de baixa tecnologia em paralisia cerebral sem comunicação oral: relato de caso. Rev CEFAC. 2004; 6(3):247-52.

6. Almeida MA, Piza MHM, Lamônica DAC. Adaptações do sistema de comunicação por troca de figuras no contexto escolar. Pró-Fono. 2005; 17(2):233-40.

7. Pires SCF, Limongi SCO. Introdução de comunicação suplementar em pacientes com paralisia cerebral atetóide. Pró-Fono. 2002; 14(1):51-60.

8. Pennington L, Goldbart J, Marshall J. Tratamiento del habla y el lenguaje para mejorar las habilidades de comunicación de niños con parálisis cerebral. La Biblioteca Cochrane Plus [on-line] 2007; (4):1-33. Oxford: Update Software. Disponível em: URL: http://www.sld.cu/galerias/pdf/sitios/ rehabilitacion-logo/terapia_paralisis_cerebral.pdf. Acesso em julho de 2008. 
9. Paula KMP, Enumo SRF. Avaliação assistida e comunicação alternativa: procedimentos para educação inclusiva. Rev Bras Ed Esp. 2007; 13(1):3-26.

10. Von Tetzchner S,Brekke KM, Sjothun B, Grindheim E. Inclusão de crianças em educação pré-escolar regular utilizando comunicação suplementar e alternativa. Rev Bras Ed Esp. 2005; 11(2):151-84.

11. Pennington L, Goldbart, J, Marshall J. Interaction training for conversational partners of children with cerebral palsy: a systematic review. Int $\mathrm{J}$ Lang Commun Disord. 2004; 39(2):151-70.

12. Pennington L, Goldbart J, Marshall J. Tratamiento del habla y el lenguaje para mejorar las habilidades de comunicación de niños con parálisis cerebral. La Biblioteca Cochrane Plus. 2007; 4:1-33.

13. Schlosser RW, Sigafoos J. Augmentative and alternative communication interventions for persons with developmental disabilities: narrative review of comparative single-subject experimental studies. Res Dev Disabil. 2006; 27:1-29.

14. Starble A, Hutchins T, Favro MA, Prelock $P$, Bitner B. Family-centered intervention and satisfaction with AAC device training. Commun Disord Quart. 2005; 27(1):47-54.

15. Saito Y, Turnbull A. Augmentative and alternative communication practice in the pursuit of family quality of life: a review of the literature. Res Practice Persons Severe Disabil. 2007; 32(1):50-65.

16. Harty M, Alant E, Uys CJE. Maternal selfefficacy and maternal perception of child language competence in pre-school children with a communication disability. Child: Care Health Dev. 2006; 33:144-54.

17. Millar DC, Light JC, Schlosser RW. The impact of augmentative and alternative communication intervention on the speech production of individuals with developmental disabilities: a research review. J Speech Lang Hear Res. 2006; 49:248-64.
18. Cardoso JL. Dialogismo e fonoaudiologia: a intersubjetividade na clínica [dissertação] Porto Alegre (RS): Universidade Federal do Rio Grande do Sul; 2002.

19. Zorzi JL, Hage SRV. PROC: Protocolo de Observação Comportamental: avaliação de linguagem e aspectos cognitivos infantis. São José dos Campos: Pulso Editorial; 2004. 93p.

20. Marchesan, IQ. Fundamentos em Fonoaudiologia: aspectos clínicos da motricidade oral. 2. ed. Rio de Janeiro: Guanabara Koogan, 2005, 160p.

21. Surreaux LM. O discurso fonoaudiológico: uma reflexão sobre sujeito, sentido e silêncio [dissertação]. Porto Alegre (RS): Universidade Federal do Rio Grande do Sul; 2000.

22. Trevizor TT, Chun RYS. O desenvolvimento da linguagem por meio do sistema pictográfico de comunicação. Pró-Fono. 2004; 16(3):323-32.

23. Bakhtin M. Marxismo e filosofia da linguagem: problemas fundamentais do método sociológico na ciência da linguagem. 7. ed. São Paulo: HUCITEC; 1995. 196p.

24. Flores VN, Teixeira M. Introdução à linguística da enunciação. São Paulo: Contexto; 2005. 125 p. 25. Foley BE, Staples AH. Developing augmentative and alternative communication (AAC) and literacy interventions in a supported employment setting. Top Lang Disord. 2003; 23(4):325-43.

26. Johson RM. Guia dos símbolos de comunicação pictórica. Porto Alegre: Clik; 1998. 64p.

27. Campbell PH, Milbourne S; Dugan LM; Wilcox MJ. A review of evidence on practices for teaching young children to use assistive technology devices. Topics Early Child Spec Educ. 2006; 26(1):3-13. 28. Schlosser RW, Sigafoos J. Augmentative and alternative communication interventions for persons with developmental disabilities: narrative review of comparative single-subject experimental studies. Res Develop Disabil. 2006; 27:1-29.

DOI: 10.1590/S1516-18462010005000068

RECEBIDO EM: 17/06/2009

ACEITO EM: 12/02/2010

Endereço para correspondência:

Ana Paula Ramos de Souza

Rua Raposo Tavares, 134 ap. 401

Santa Maria - RS

CEP: $97015-560$

E-mail: ramos1964@uol.com.br 